\title{
Measuring the Economic Benefits of E-Learning: A Proposal for a New Index for Academic Environments
}

\author{
Agostino Marengo and Vittorio Marengo \\ Faculty of Economics - University of Bari, Bari, Italy
}

amarengo@dss.uniba.it vmarengo@dss.uniba.it

\section{Executive Summary}

The aim of this paper is to transform the necessity for "integrated ICT training" in study courses within universities into a possible action plan which indicates both the pros and cons of the use of IT in the strategies, services and products to be used from a cost point of view.

This will enable an evaluation of the Return On Investment (ROI) using the new concept of Yield Index "e-lYI" (e-learning Yield Index), introduced in this study. The Yield Index "e-lYI" suggests an original way to evaluate the implementation of e-learning methodologies into campus based environments; still, the new index will help professionals involved in the management of the transition from the "classical" university structure to the innovative structure needed by the elearning implementation. These results should interest any Faculty or University which is planning to introduce e-learning methodology to its didactic organization.

In this study, a Pilot Course, delivered in "Blended" learning model, will be taken into consideration to estimate the costs. In the subsequent phase the ROI will be assessed for the Pilot course and compared to the ROI of a classical course by the use of "e-lYI".

Furthermore, it would therefore be extremely interesting to consider the "e-lYI" in a University administration that decided to adopt an Open Source Learning Management Systems. Open Source, therefore, will be the final element of innovation and experimentation in the evaluation process.

Keywords: e-lYI, ROI, e-learning, costs, evaluation, open source.

\section{Introduction - The Context}

In the last five years, European Public Administration, in particular that within universities, has shown renewed interest in applications geared to information technology training. Its subsequent

Material published as part of this journal, either on-line or in print, is copyrighted by the publisher of the Journal of Information Technology Education. Permission to make digital or paper copy of part or all of these works for personal or classroom use is granted without fee provided that the copies are not made or distributed for profit or commercial advantage AND that copies 1) bear this notice in full and 2) give the full citation on the first page. It is permissible to abstract these works so long as credit is given. To copy in all other cases or to republish or to post on a server or to redistribute to lists requires specific permission and payment of a fee. Contact Editor@JITE.org to request redistribution permission. rapid development has helped accelerate and optimize knowledge of IT, overcoming the barriers of time and space which are characteristic of traditional training.

The European Union Council, during a meeting in Lisbon in 2000, recommended that national governments organize a rapid acceleration in IT training to adopt the levels necessary 
for the European society of the third millennium.

Following this recommendation, the European Community Commission adopted an initiative entitled "e-Learning - considering tomorrow's training". All member states were asked to "persevere in efforts to integrate information and communication technologies in teaching and training" and to "take advantage of the potential of internet, multimedia and virtual learning systems to realize in as short a time as possible an improved and permanent education."

These measures, initially aimed solely at strengthening infrastructures and equipment, are increasingly directed towards other areas; teaching content, ensuring quality and standards, training the trainers themselves, organizational changes, the transformation of education and training processes and the training and re-skilling of public sector employees.

\section{Study Objectives and Methodology}

The principal objective is to set up a possible action plan which indicates both the pros and cons of the use of IT in the strategies, services and products to be used from a cost point of view.

The authors considered that in the late 1980s Gartner examined the full costs related to desktop technology, and Ted Bullen, a strategic consulting manager at IBM, laid out the specific costs for the lifecycle of a PC including planning, purchasing, deployment, support, asset management, and disposal.

This will enable an evaluation of the Return On Investment (ROI) using the new concept of Yield Index "e-lYI" (e-learning Yield Index), introduced in this study. These results should interest any Faculty or University which is planning to introduce e-learning methodology to its didactic organization.

The Yield Index "e-lYI" suggests an innovative way to evaluate the implementation of e-learning methodologies into campus based environments; and still the new index will help to manage the transition from the "classical" University structure to the innovative structure needed by the elearning implementation.

In this study, a Pilot Course will be taken into consideration and Critical Success Factors will be defined, factors innate in any Blended course.

In the subsequent phase, costs will be estimated and the ROI and "e-lYI" assessed for an elearning course. It should be borne in mind that the costs of planning and operating such a course, as well as those of its methodology evaluation, could be much lower if a Faculty decided to standardize this method and use the competencies acquired for other courses offered.

The pilot course was based in a remote locality: how will the cost and ROI differ if the course is Blended rather than Face-2-Face (F2F)? How can a Faculty decide which course is more appropriate? How can the Yield Index e-lYI be used to understand whether such a change will be successful from a quality and economic point of view?

It must be seen through the e-lYI that the choice of an e-learning based course is a positive one for the administration. What would be the end result if a Faculty decided to establish a series of Blended courses (rather than a single one)? Would the ROI increase or decrease? What would happen to the e-1YI?

Furthermore, the management of a University needs to allow for increasingly more budget cuts. It would therefore be extremely interesting to consider the ROI in a University that decided to adopt e-learning practices for institutional training through the Open Source Learning Management Systems. Open Source, therefore, will be the final element of innovation and experimentation in the evaluation process. 
This paper discusses a recommended training approach that will allow a Faculty to deliver effective training into a distributed region at a reasonable cost, maximizing the benefits of implementing any technology solution. It's not a reinventing of activity based costing but, chiefly, an evaluation of costs parameters related to the academic environment; the aim is to achieve a sort of "comparison tool" to evaluate the real possibilities for a Faculty to project and realize a course using e-learning technologies and methodologies. With this aim the paper introduces the "elearning Yield Index" tool.

A series of user-friendly tools (Clark \& Mayer, 2003) will be provided so that the designer/evaluator can immediately understand:

- During a feasibility study, the certainty that there is a genuine opportunity for improvement in the quality of the training offered, providing, at the same time, an overview of the costs and benefits;

- During evaluation both on- and off-site, the project trends in terms of costs, benefits and teaching quality;

To help understand the situation more clearly, an explanation of the pilot course (to be referred to throughout the study) follows:

\section{Pilot Course Description}

The course described was held in a remote locality (situated, typically, about $100 \mathrm{Km}$ from the central administration) which the Faculty has identified as a high-user catchment's area to justify the opening of a remote centre. A course on IT Systems applied to Business Management for third year Economics students was held; the course is worth 5 University credits, each credit based on 25 study hours, 10 of which in the classroom. The total number of lesson hours is 50 .

The number of students following this course is between 50 and 100 a year. The Faculty usually organizes the lessons externally in regional or civic teaching centres with either professors from the Faculty or, occasionally, external professors.

In this scenario the e-lYI has been used for understanding with accuracy the differences of costs using e-learning in comparison with classical teaching methodologies applied in that remote learning centre identified by the Faculty.

This paper explains that the choice is not simple and immediate, especially using the ROI values, but the use of e-1YI introduces a clean simplification both the existing theory, introducing a data optimization principle, and the concrete analysis, assuming a tangible parameter of comparison.

\section{Critical Success Factors In E-Learning Courses}

To better understand the significance of CSF in e-learning course, the authors think it's useful to quote some passages from an interesting White Paper from Radiant Systems (Radiant Systems, 2002) in which are highlighted some specific characteristics reported below.

Before finalizing the training strategy, the organization will need to formulate responses to these critical questions:

1. What training delivery modes will the organization use? For which audiences?

2. If using classroom training, will it be regional or will learners travel to one location?

3. How will the organization map the overall training program to the program implementation? 
4. What tool will the organization use to launch the e-learning content?

5. Who will develop the initial training materials including manuals and e-learning courses?

6. Who will maintain it moving forward?

7. How will the organization determine training success?

In this section, critical questions are applied to the pilot scheme defined in the previous section:

1. The training delivery modes will be of the Blended variety with predefined F2F meetings before, during and after the course as well as before exam sessions; the participants are taken from students in at least their third year of study and appropriate maturity and self-management are expected;

2. Students are all resident in areas distant from the principal Faculty building; the majority live near the decentralized facilities in which the F2F courses are held;

3, 4 and 5. The organization will adopt a system of e-learning based on a Learning Management platform which will manage course content to international standards (SCORM) and will be implemented by appropriate HW and SW support.

6. The management of the learning platform and its content will be the responsibility of a team of professionals with different competencies, trained specifically for the project (to be discussed later on).

7. The evaluation of teaching quality will be determined by traditional methods of interview and exam, while the evaluation of the ROI will be discussed further later on.

There are many critical steps in developing and executing a successful learning program. The following is a list, quoted again from Radiant Systems White Paper (Radiant Systems, 2002), of a few of the top actions to ensure the success of the program:

- Conducting a thorough analysis and developing a training plan leads to the most efficient and effective learning solutions;

- Using a blended approach to training including classroom training, synchronous and asynchronous online training, and printed materials supports training for a widely distributed and changing audience;

- Developing e-learning content that is interactive, relevant to the audience, and includes the whys as well as the how will keep learners engaged and increase overall knowledge retention;

- Marketing the e-learning through a variety of mediums prepares and excites users for the new methods of training delivery;

- Allowing adequate time for e-learning on the job and ensuring managers support this type of learning increases the completion rate for self-paced learning;

- $\quad$ Tracking results and tying to performance reviews holds learners accountable no matter what delivery mode is selected;

- Providing adequate technical and operational support during training and after go-live for end users decreases frustration; 


\section{Focusing the training investment}

Last, useful concepts from Radiant Systems' White Paper (Radiant Systems, 2002) are considered below to better understand in which way the training investment will be focused in addition to learning style.

There are several factors to consider when determining the training approach that is best suited for the program being developed. These factors include learner population, the technical level of the content, average employee tenure in that role, and geographic distribution of the learners.

Learner population. In general, the larger the audience, the more scalable the training program needs to be. A highly scalable training program might consist of a combination of e-learning and instructor-led training where the basic content is covered in e-learning and instructor-led training is utilized to address collaborative, high impact items such as business process change and sharing of best practices.

Technical level of content. Typically, the more basic the content, the easier it is to develop training in a variety of formats. As content becomes more technical in nature - for example, when training the help desk or system administrators - so does the need to incorporate more detailed hands-on simulations. While these can be addressed via elearning, the cost to do so may be prohibitive.

Geographic distribution. Travel costs associated with delivering classroom training to a widely distributed learner population can be enormous, and such an audience can benefit greatly from centralized, consistent training whether delivered via e-learning or a virtual classroom.

\section{Cost Factors}

The economic study of an e-learning project is a complex activity, involving, as it does, business, economic and extra economic factors.

Given such complexity, it is perhaps more important to understand first all of the economic factors which can influence the training process and thus the characteristics, interaction and behaviour, the context and conditions of which these factors determine. This knowledge allows us to identify which combination of factors is best suited to satisfy the specific training needs for the subject of the analysis. An analysis of cost items (Horton, 2002) will be provided. As well as being grouped into typologies, each item will be examined to determine the following characteristics with a view to determining the cost structure:

Degree of Variability. For each item, the degree of independence or dependence on the three areas which traditionally characterize a training procedure;

1. The number of students benefiting from the training

2. The distances involved

3. The duration of the training procedure

Cost allocation. This characteristic shows whether the cost shows its benefit solely for the training procedure being evaluated or also on other factors. In the first scenario, the entire cost incurred has to be considered in the cost benefit analysis. In the second, only a proportion of the cost needs to be allocated. 


\section{Costs due to technological factors: HW and SW}

The first group of costs which must be carefully studied (Allan, 2002; Bracchi, Francalanci, Motta, 2003; Radiant Systems, 2002) is that relative to the technology used in e-learning activities (see Table 1). Its principal characteristics can be summarized as follows:

Digital content costs. The digital content of the course can either be developed internally or bought externally. In both cases, this is the most important factor in increasing total costs for the entire training process. In order to obtain digital products that are didactically useful, it is often necessary to use professional figures not required in traditional training programmes (as a case in point, see the ETM - Expert In Multimedia Technology - section below).

In the scenario of external purchase, it should be borne in mind that the cost can be divided into annual instalments. In this case, the cost should be considered variable, based on the duration of the teaching program and how often this may be repeated during the training project.

The degree of variability of this cost item is essentially zero with respect to the number of students and the number of training program and their duration.

Maintenance costs for digital content. Due to the changeable nature of the digital content of the course, any cost estimate should include costs incurred in updating in future years. This item has the same variability characteristics as the previous section.

Content hosting costs. The continued usability of the digital content is possible due to its storage in server archives. It can be hosted by an external web space supplier or by a company's own server. The annual cost of hosting should be reconsidered each new academic year. This cost item is also independent of student numbers and distances. However, it does present a certain variability degree with regard to the number of courses to be held: indeed, the higher the hosting capacity, the higher the cost of renting server space (external hosting) or the costs incurred in using this space (internal hosting).

Distribution Costs. In cases in which the course content is hosted externally, a server connection will be necessary. The cost corresponds either to that of telephone line connection (average connection time per student multiplied by estimated number of students) or the fixed cost of broad band and satellite connection.

Learning Management System costs (LMS). Without doubt, the greatest cost incurred is that of buying an LMS. In any e-learning evaluation, this item should be considered bearing in mind the context of a University administration interested in adopting this teaching format for a long period of time. The item (Jain, 2002) constitutes an investment over a period of time and its continued use over the years justifies splitting the expenditure into annual instalments. In evaluating non-systematic, one-off e-learning procedures which do not imply a complete transition to this technological training approach, this item should not be considered as it is reasonable to assume that the company will not buy an LMS. As regards the costs of personalization and maintenance (Horton, 2002) of the LMS (but not that of the license), these are usually annual and will need to be multiplied by the duration time of the e-learning project. The degree of variability for this item is not applicable as again, when compared to factors such as the number of students following the course and their distance as well as the number of courses themselves, this particular item shows a minimal variability.

Hardware and software costs. In cases where the hardware and software supplied by the Faculty to circulate the contents are not sufficient, the e-learning evaluation needs to take into account the cost items such as purchase of a server and its relative software and the cost of web access. As regards its allocation, this item can be spread across numerous teaching programs (this solution appears that used most often) or concentrated on one program only. The wiring costs depend on 
the system that needs to be installed as well as the distances involved but are independent of the number of students involved in the program.

Table 1: Cost Factors - Technology Point of View

\begin{tabular}{l|l|l|l|l|}
\hline \multicolumn{1}{c|}{ Cost } & \multicolumn{1}{c}{$\begin{array}{c}\text { Number of } \\
\text { students }\end{array}$} & \multicolumn{1}{c}{ Distance } & \multicolumn{1}{c}{$\begin{array}{c}\text { Course } \\
\text { duration }\end{array}$} & $\begin{array}{c}\text { Value compared to } \\
\text { traditional training }\end{array}$ \\
\hline Content development. & Fixed & Fixed & Fixed & EXCLUSIVE (High) \\
Hosting content. & Fixed & Fixed & VARIABLE & EXCLUSIVE (Low) \\
Maintenance content. & Fixed & Fixed & VARIABLE & EXCLUSIVE (High) \\
Distribution content. & VARIABLE & Fixed & Fixed & EXCLUSIVE (Low) \\
LMS & & & & \\
$\cdot$-Licence & Fixed & Fixed & Fixed /VAR & \\
$\cdot$-Installation & Fixed & Fixed & Fixed & EXCLUSIVE (High) \\
•Pers/Man & Fixed /VAR & Fixed & Fixed /VAR & \\
$\cdot$ •Hosting & Fixed & Fixed & VARIABLE & \\
Technological & Fixed/VAR & VARIABLE & Fixed & EXCLUSIVE (High) \\
Infrastructure. & & & & \\
\hline
\end{tabular}

\section{Trends and aspects of technological costs}

Technological costs represent the principal item (Bracchi, Francalanci, \& Motta, 2003) in the overall budget when evaluating an e-learning project.

The cost trend for IT systems for web-based teaching appears to be decreasing, as has already happened for other IT applications. Therefore we can expect better performance at a similar cost or similar performance at a lower cost. In both cases there appears to be an optimistic outlook for a more attractive relationship between total costs and e-learning benefits.

In the meantime, the technical possibilities of hardware and software are rapidly increasing, further improving the efficiency of e-learning. One need only consider the fact that in recent years, the field of IT and data transmission is one that has benefited most from technical advances and in which research has been most prolific.

A further element which may reduce e-learning costs is that of the standards for e-learning program on the market. The implementation of international standards and their recognition will eventually lead to:

a. The possibility of using training content in different platforms without having to buy new ones;

b. The possibility of using content and software and hardware for e-learning from different manufacturers.

This will in turn lead to more suppliers for the market with a subsequent benefit in terms of prices.

It is also worth noting that the e-learning market is an extremely recent one. One can reasonably expect, therefore, that its development will lead to increased competition and consequently, a lowering of prices. 
Volatility of course content and productions values are important issues as is the nature of competition and marketing in the higher education sector. The influence of badge marketing by prestigious universities has the potential to distort the market and lead to a portfolio approach to education. The quote from Merrill Lynch stating $3 \mathrm{c}$ per hour is a reasonable figure compared to $\$ 300$ per hour for conventional methods is questionable at best and ignores questions of scalability in hardware, bandwidth and licensing provision. As expressed it is merely a description of an audit tool for decision support. Questions of strategy and entrepreneurship are not addressed.

\section{Costs of e-learning staff}

Tutoring costs. Some course content requires the presence of a member of training staff during the planning and implementation stages to bridge the competency gap for each training process (see Table 2). The degree of variability for this cost item is closely linked to the number of students to be assisted and the duration of the training program. The item is, however, totally independent of the distance over which assistance is provided.

ETM training costs. As shown in the Corano Project (Filetti, Marengo, Pioppi, Ropa, \& Uscidda, 2002), the role of the teacher is continually evolving as increasing numbers of information sources become available through networking developments. In this new context, the teacher is lent increasing support by someone who can define didactic methods and strategies which identify the best way to present the information available. It is therefore necessary to introduce support staff to work alongside teachers and who are able to improve the learning process.

The innovative staff role proposed is that of the designer and developer of multimedia, interactive and virtual settings, the Expert in Multimedia Technology or ETM. The ETM has to support teachers in the activities of organization and management and, to some extent, the development of online courses as well. The ETM should be trained within the University structure.

Administration and management costs. As is the case with traditional training courses (Holton \& Baldwin, 2003), on-line training also requires a certain degree of administration. This cost item has a minimum degree of variability regarding student numbers and distances as IT system administration is barely affected by variations in the number of users. The degree of variability is, however, higher with regard to the duration of the project as system administration staff remuneration will be multiplied by the time for which this administration itself is necessary. Due to its indirect nature, this cost element should be divided among a variety of courses.

Consultancy costs. E-learning is a new sector and its principal features are relatively unfamiliar to many organizations. In the initial phase of implementing a training system of this type, it may be useful for the Faculty to employ external specialist consultants to define this innovative strategy and put it into practice. The cost of consultancy is separate from all the characteristics so far indicated for the other cost items.

Costs for synchronous teaching. In situations of synchronous learning, the teacher-facilitator needs to be present. A cost item for the remuneration of these employees should therefore be included. The number of participants in synchronous activities and their duration should be considered carefully. The distance factor of users is of no consequence as regards synchronous activity. 
Table 2: Cost Factors - Personnel Point of View

\begin{tabular}{llllll|}
\hline \multicolumn{1}{c|}{ Cost } & $\begin{array}{c}\text { Number of } \\
\text { students }\end{array}$ & Distance & $\begin{array}{c}\text { Course } \\
\text { duration }\end{array}$ & $\begin{array}{c}\text { Value compared to } \\
\text { traditional training }\end{array}$ \\
\hline $\begin{array}{l}\text { Technical tutoring } \\
\text { ETM training costs }\end{array}$ & VARIABLE & Fixed & VARIABLE & Higher \\
$\begin{array}{l}\text { Administration } \\
\text { e management }\end{array}$ & VARIABLE & Fixed & Fixed/VAR & NOT EXCLUSIVE \\
$\begin{array}{l}\text { External consultancy } \\
\text { Synchronous teaching }\end{array}$ & Fixed & FARIABLE & Fixed & Fixed & Higher \\
\hline
\end{tabular}

For a deeper treatment of the costs of e-learning staff, see Miller \& Kulik (2000).

\section{General costs}

Promotional costs. When a cost analysis is carried out in the context of a complete macro change in the company training program and not just for one or two courses, it may be necessary to incur costs in sensitizing the departments within the company who will be involved in the transition. (Hall \& LeCavalier, 2001). The allocation of this cost (see Table 3) item is multiple and is almost totally independent of the number of personnel and distances involved, as well as the training duration.

Costs of e-learning support. Once again, in any macro change, it may be necessary to incur costs in ensuring efficiency for e-learning action; for example, the possible costs involved in basic IT training for students due to participate in the courses.

Table 3: Cost Factors - General Point of View

\begin{tabular}{|l|l|l|l|l|}
\hline \multicolumn{1}{|c|}{ Cost } & $\begin{array}{c}\text { Number of } \\
\text { students }\end{array}$ & \multicolumn{1}{c|}{ Distance } & $\begin{array}{c}\text { Course } \\
\text { duration }\end{array}$ & $\begin{array}{c}\text { Value compared to } \\
\text { traditional training }\end{array}$ \\
\hline Promotion & Fixed & Fixed & Fixed & Higher \\
e-1 support & VARIABLE & VARIABLE & VARIABLE & Higher \\
\hline
\end{tabular}

\section{Kirkpatrick's Taxonomy in an Academic Environment}

Company evaluation of ROI in e-learning presents different characteristics from that of cost evaluation and is also somewhat more complex. The environment in which this evaluation takes place, the Italian University system, also needs to be considered; generally speaking, it is similar to a company environment but has several major differences, most notably the fact that the inherent objective of the institution, didactic activity, is directed not only at users (i.e. students) but also staff (although in a different way).

Students are the major "clients" of the University and for this reason, the reaction of students to the proposed training process needs to be evaluated. Student reaction is also needed regarding the quality of teaching as applied to improvement in exam performance and the improvement of economic conditions via the system of allocation.

The theoretic model used in any evaluation process of this type is that of Kirkpatrick (see Table 4), which also forms the conceptual theory for this study with slight modifications to adapt it to the needs of an academic institution (Calvani \& Rotta, 2000). 
Given this context, the four levels of Kirkpatrick's evaluation can be defined as follows;

Table 4: Kirkpatrick's Taxonomy

\begin{tabular}{|l|l|}
\hline Reaction & $\begin{array}{l}\text { Measuring the reaction of the students and their perception of the teaching activity } \\
\text { attended. This is done by questionnaire at the end of the course to gauge the level of } \\
\text { satisfaction with the organisation, logistics and social aspects of the course. }\end{array}$ \\
\hline Teaching quality & $\begin{array}{l}\text { Measuring the improvement in competency, ability and capacity, skills which have } \\
\text { been acquired due to the training activities and which principles, techniques and be- } \\
\text { haviour have been understood and acquired by students. This is considered the prin- } \\
\text { ciple objective of the training project. }\end{array}$ \\
\hline Progress & $\begin{array}{l}\text { Measuring the improvement in work activity after the training course; clearly, this } \\
\text { level is not applicable in a University environment. }\end{array}$ \\
\hline Economic results & $\begin{array}{l}\text { Measuring the economic improvements that the University administration benefits } \\
\text { from through the use of e-learning (cost reduction, improvements in quality, etc.). }\end{array}$ \\
\hline
\end{tabular}

This study will concentrate on the fourth level of Kirkpatrick, evaluating the economic results, but will also take into account the first two levels due to their use in measuring the quality of a training process.

\section{Benefit factors}

The evaluation of the benefits of implementing Blended e-learning is significantly more complex than that of cost evaluation as it can be found in every evaluation level outlined in Kirkpatrick's taxonomy.

In this analysis, the first group of benefits can be labelled exclusive, the value of which can be seen as directly attributable to e-learning innovation. As these benefits are difficult to measure in monetary terms, a comparison with economic analysis would be complicated, because both, costs and benefits, could be minimized or maximized in relation to the context in which we'll analyze them.

The other benefits of e-learning for the organization can be divided into two types: savings made compared to traditional training and material benefits compared to other teaching methods. There follows an analysis of the first and more obvious category.

\section{Savings made compared to traditional training}

The Open University (London, England) is well-known not only in the University environment and they have stated that the cost of on-line courses may well be about $45 \%$ of that of traditional courses. The Open University has running costs of approximately half of those of traditional universities. The average class size is approximately 200 people.

An attempt can thus be made to group the various "savings" items which are attributable to elearning:

Reduction in travel expenses. This is the most immediately recognizable advantage. In a University context, this is applicable as the cost of teacher travel to remote locations for F2F lessons as well as that of the technical-administration staff who assist with course management.

Reduction in teaching remuneration. A University may need to repeat the same course for different students. It should be noted that these costs are incurred for each training session carried out. 
Therefore an evaluation of the saving made should be multiplied by the number of sessions necessary to complete the training process.

Reduction on costs for materials. This item refers to the costs of the creation (printing, masterizing of CD-ROMs, etc.) and distribution, storage and management of training materials (books, handouts, CD-ROMs, etc.), costs which are destined to be repeated with every content update. Naturally, the creation and changes of e-learning course content will incur costs but tend to follow the downward cost trend previously described for ITC technology. The content distribution cost is practically non-existent.

\section{Material benefits compared to other teaching methods}

The material impact on work (Henderson, 2003) is also a benefit item which is recognisable and convertible. The following factors should be considered in the case of e-learning:

Poor quality competency acquisition due to insufficient, delayed or incomplete training. In some situations, the very means of training are compromised by problems of physical space or time. It may be impossible to find the necessary classroom space or to complete the course in time.

Eliminating these two problems (completely in the case of non-synchronous training solutions, partially in that of mixed programmes) allows the Faculty to reduce or overcome the obstacles referred to above with a consequent effect on the quality of the training programme.

Increase in individual study time. The use of e-learning methodologies and technologies means that as the need to travel to the learning premises is reduced, the student can dedicate this time to study activities set out in the lessons.

Reduction in training time. Studies have found that with e-learning, the time needed to reach the same learning objectives (Kirkpatrick level 2) is inferior to that of traditional courses. Research on Computer Based Training at the Hudson Institute of Indianapolis over a period of 20 years has revealed an average time reduction of $40 \%$. One of the key factors in this is a supposed greater training efficiency in ICT programmes. If this is so, the additional time could be used for individual study, time that other training methods would use for F2F teaching.

Some doubts remain as to whether time reduction really is a result of greater efficiency in elearning.

The final group of benefits to be identified is that of Organizational Benefits. This type of benefit is particularly difficult to highlight and measure and can be defined as that which the organizational structure gains from the use of e-learning methodologies (not other training types) due to the substitution of teaching systems with IT systems; it is these that provide the identity of the technological means being used. This factor allows for a synergy that traditional training methods can not.

The management of resource knowledge and the potential to create virtual learning communities are potential advantages that only e-learning can offer. Even if these advantages are not explicitly economic, their indirect economic implications are extremely important.

\section{The "e-IYI" Yield Index}

Although an ROI calculation (Kossmann, 2004) can go a long way toward measuring or predicting the business results of teaching/learning, it should never be the final word. Training is a messy business and returns come in many forms, some of which cannot yet be reduced to bottomline figures. 
In some cases, the training manager may chose to stick with conventional training because the returns are more predictable and safe. In others, further investments in e-learning may be justified because e-learning requires the organization to develop new skills, to capture knowledge in a more tangible and reusable form, and to recruit and retain new talent. All these actions increase the intellectual capital of the Faculty, though they are hard to capture in an ROI calculation.

Because the ROI is so widely used to evaluate the business success of large, complex projects like e-learning, it will be important to explain a useful technique of calculating ROI in academicals environment using Open Source systems and comparing e-learning training costs with classical "face to face" training costs.

The basic formula for calculating ROI, as shown in Equation 1, is quite straightforward, the costs analyst has just to subtract costs from benefits, divide that difference by costs, and then multiply the results by 100 :

$$
\text { ROI }=\frac{\text { Benefits }- \text { Costs }}{\text { Costs }} \times 100
$$

The term [Benefits minus Costs] represents the Return On The Project. The investment is the costs of the project or at least the up-front costs.

To complete this study and for a greater understanding of the concept of ROI, an index is provided below which makes an interesting comparison between traditional didactics and e-learning. In many cases, there is a need for an instrument which can instantly indicate the feasibility and necessity of e-learning; events such as Faculty meetings will often see a debate into the necessity and applicability of venturing into this area.

The e-learning Yield Index, or e-IYI, as shown in Equation 2, represents the rapport between the $\mathrm{ROI}$ of classic teaching programs ( $\mathrm{ROI} \mathrm{cl}$ ) and that of the same programs in e-learning mode (ROI e-1):

$$
e-l Y I=\frac{R O I_{e-l}}{R O I_{C L}}
$$

The e-1YI can incontrovertibly determine whether there is a need for e-learning as part of a course, provided that this is a comprehensive change, i.e. the transformation of an F2F course into one developed through e-learning methodology, such as a Blended course.

In the pilot course, the change from traditional style to e-learning Blended is desirable where:

- The change is carried out by a group with competencies which include ETM and experts in content and communications (in addition, obviously, to the teaching staff).

- The development, implementation and evaluation use Deming's classic model for IT systems in order to obtain reliable instruments for the evaluation and improvement of training projects;

- The e-1YI is greater than 1, so that the traditional ROI is inferior to the e-1 ROI. In this way reliable data can be obtained on the results in economic terms.

It can be seen, however, that the e-1 ROI is a factor reliant on numerous variables which can contribute to the end result. Therefore it is necessary to verify that the e-lYI is greater than 1 in the phases of both feasibility and start-up as well as that of the installation of the training project.

The advantage of this index becomes clear in the evaluation phase of the project. In referring to the e-IYI, it will be possible to evaluate at any given time: 
- The accuracy of the feasibility study;

- The need to change any expenditure parameters;

- The possibility of increasing the training program offered by adding new teaching instruments on-line;

If used as a monitoring instrument within a Faculty, the e-1YI index helps evaluate the possibility of "transforming" other courses of study into e-learning to increase the benefits of the training programs offered and thus lead to a greater efficiency in the ROI.

\section{Evaluation of Cost and Benefit Factors}

\section{Benefits}

The concrete benefits indicated below are relative to the e-learning Blended methodology implemented in the pilot course. Each item is given an acronym to help define the benefits addendum more clearly in the ROI formula:

- Reduction in travel expenses: $\mathrm{B}_{\mathrm{rsv}}$;

- Reduction in teaching remuneration: $\mathrm{B}_{\mathrm{rcd}}$;

- Reduction in costs of materials: $\mathrm{B}_{\mathrm{spm}}$;

- Reduction in client support costs: $\mathrm{B}_{\mathrm{csc}}$;

The non-material benefits indicated below are considered as factors in the overall evaluation; they will be added to the benefits part of the ROI formula as a percentage and will be evaluated through interviews with participants involved in the training programme:

- Quality of the skills acquired by the student: $\mathrm{B}_{\mathrm{qas}}$;

- Increase in productive time per individual: $\mathrm{B}_{\mathrm{tp}}$;

- Reduction in teaching time: $\mathrm{B}_{\mathrm{rtf}}$;

- General organisational benefits: $\mathrm{B}_{\text {org }}$;

The determination of the Benefits item is shown below in Equation 3:

$$
B_{t o t}=\frac{\left(B_{r s v}+B_{r c d}+B_{s p m}+B_{\mathrm{csc}}\right)}{B_{t p i} \bullet B_{r t f} \bullet B_{o r g}} \bullet B_{q a s}
$$

The non-material benefits, stated as a percentage, are multiplied or divided depending on their contribution as negative or positive.

For example, the value Bqas is shown on the numerator as the maximum value of quality in $\mathrm{F} 2 \mathrm{~F}$ lessons is equal to 1 . As a result Bqas will only be a percentage of the maximum, a percentage that becomes evident through interviews or exams taken. In a scenario where the average quality of skills acquired by students is $70 \%$ compared to that reached in an F2F course, the value of Bqas will be 0.7 . The value of the total benefit is thus reduced by $30 \%$. The same method is used for the other three values which make up non-material benefits. 


\section{Start-up costs}

Cost factors were outlined in a previous section. In this section, the most important of these are selected from an academic/University perspective and their importance evaluated for ROI and Yield Index purposes, as you can see in Equation 4. These cost factors are as follows:

- Cost of creating digital content: $\mathrm{C}_{\mathrm{rcd}}$;

- Cost of maintenance of digital content: $\mathrm{C}_{\mathrm{mcd}}$;

- Cost of content hosting: $\mathrm{C}_{\mathrm{hcd}}$;

- Cost of content distribution: $\mathrm{C}_{\mathrm{dcd}}$; this item is not applicable to universities which should have multimedia classrooms in which students can use Internet and PCs; the item is included here to complete the list of factors in a comprehensive way.

- Cost of Learning Management System: $\mathrm{C}_{\mathrm{lms}}$;

- Cost of HW (Hardware) and SW (Software) infrastructures: $\mathrm{C}_{\mathrm{hwsw}}$;

- Teaching costs: $\mathrm{C}_{\text {tut }}$;

- ETM training costs: $\mathrm{C}_{\mathrm{etm}}$;

- Administration and management costs: $\mathrm{C}_{\mathrm{amge}}$;

- Consultancy costs: $\mathrm{C}_{\text {cons; }}$;

- Synchronous teaching costs: $\mathrm{C}_{\text {docs; }}$;

- Promotion costs: $\mathrm{C}_{\text {prom; }}$;

- e-learning support costs: $\mathrm{C}_{\mathrm{wb}}$;

Determination of the Start-up Costs item:

$$
\begin{aligned}
& C_{\text {totsU }}=C_{r c d}+C_{m c d}+C_{h c d}+C_{d c d}+C_{\text {lms }}+ \\
& +C_{h w s w}+C_{t u t}+C_{e t m}+C_{\text {amge }}+C_{c o n s}+C_{\text {docs }}+C_{\text {prom }}+C_{w b t}
\end{aligned}
$$

\section{Operation costs}

In calculating system costs, those incurred in starting the project should be detracted from the total as follows:

- $\mathrm{C}_{\mathrm{rcd}}$, as contents are only maintained;

- $\quad \mathrm{C}_{\mathrm{lms}}$, as the LMS (Learning Management System) platform cost is paid off during the period of use and as such only the costs of hosting and maintenance need to be met.

- $\mathrm{C}_{\mathrm{hwsw}}$, as both hardware and software are costs relative to the start of on-line teaching activities;

- $\mathrm{C}_{\text {etm }}$, the ETMs will already have been trained and can be used as trainers themselves for new ETMs;

- $\mathrm{C}_{\text {cons }}$, consultancy is necessary at the start of the project but not as much during it.

The Total Operation Cost, as shown below in Equation 5, can be given by the total:

$$
C_{\text {totREG }}=C_{m c d}+C_{h c d}+C_{d c d}+C_{\text {tut }}+C_{\text {amge }}+C_{\text {docs }}+C_{\text {prom }}+C_{w b t}
$$


Bearing in mind that the operation costs do not include the cost of the LMS platform and the HW and SW, it can be seen that start-up costs will be much lower without including the other items that have a notably inferior value.

\section{Costs of $\mathbf{N}$ courses}

Supposing the Faculty or University decides to activate N number of e-learning courses; what happens to the costs?

Some, but not all, cost factors are multiplied by the $\mathrm{N}$ courses organized. This means that the more courses organized in a Faculty, the less the relative costs incurred will be (expressed as a percentage).

A detailed breakdown is as follows:

- Costs of creating digital content: $\mathrm{C}_{\mathrm{rcd}}$ - are multiplied by the number of $\mathrm{N}$ courses as long as these do not form part of other degree courses but retain (as often happens) the same content and ideally the same teachers; $\mathrm{C}_{\mathrm{rcdN}}<\mathrm{N} \mathrm{x} \mathrm{C}_{\mathrm{rcd}}$;

- Cost of digital content maintenance: $\mathrm{C}_{\mathrm{mcd}}$ - the same conditions as above; $\mathrm{C}_{\mathrm{mcdN}}<\mathrm{N} \mathrm{x} \mathrm{C}_{\mathrm{mcd}}$

- Costs of content hosting: $\mathrm{C}_{\mathrm{hcd}}$ - these are not multiplied by $\mathrm{N}$ as long as the hosting contract has enough space to hold a large quantity of information and documents; $\mathrm{C}_{\mathrm{hcdN}}<\mathrm{N} \mathrm{x}$ $\mathrm{C}_{\mathrm{hcd}}$;

- Costs of the Learning Management System: $\mathrm{C}_{\mathrm{lms}}$ - are not multiplied by $\mathrm{N}$ as long as the performance of the LMS is sufficiently high; if the LMS is an Open Source type, this issue is not raised; $\mathrm{C}_{\mathrm{lmsN}}<\mathrm{N} \mathrm{x} \mathrm{C}_{\mathrm{lms}}$;

- Costs for the HW e SW infrastructure: Chwsw - are not multiplied by $\mathrm{N}$ but by a factor with a much lower value which is evaluated during the feasibility study; $\mathrm{C}_{\mathrm{hwswN}}<\mathrm{N}$ x C $\mathrm{C}_{\mathrm{hwsw}}$;

- Teaching costs: $\mathrm{C}_{\text {tut }}-\mathrm{a}$ technical tutor is able to carry out the same function for more than one course. As a result, one technical tutor could be proposed for every 8 to 10 courses organized. The issue changes if the tutor is responsible for contents that depend on the course type and their compatibility.; $\mathrm{C}_{\mathrm{tutN}}<\mathrm{N} \mathrm{x} \mathrm{C}_{\text {tut }}$;

- $\quad$ ETM training costs: $\mathrm{C}_{\text {etm }}$ - these do not change where the number of $\mathrm{N}$ courses vary as long as management implement training with a considerable number of ETMs; $\mathrm{C}_{\text {etmN }}<\mathrm{N} \mathrm{x} \mathrm{C}_{\text {etm }}$;

- Administration and management costs: $\mathrm{C}_{\text {amge }}$ - these vary considerably where there is an increase in the number of $\mathrm{N}$ courses, depending on the number of staff employed and the number of courses organized. Where a high number of courses are organized, it is advisable to set up an administration and management section at Faculty or University central office level; $\mathrm{C}_{\text {amgeN }}<\mathrm{N} \mathrm{x} \mathrm{C}_{\text {amge }}$;

- Consultancy costs: $\mathrm{C}_{\text {cons }}$ - the consultancy needed is that for technology and communication and can certainly be implemented using the philosophy of knowledge sharing. Where possible, staff could be trained in specific skills rather than acquiring external help; $\mathrm{C}_{\text {consN }}$ $<\mathrm{N} \mathrm{x} \mathrm{C}_{\text {cons; }}$;

- Synchronous teaching costs: $\mathrm{C}_{\mathrm{docs}}-$ depend on the number of $\mathrm{N}$ courses organized; $\mathrm{C}_{\mathrm{docs}} \mathrm{N}$ $=\mathrm{N} \times \mathrm{C}_{\mathrm{docs}}$; 
- Promotion Costs: $\mathrm{C}_{\text {prom }}$ - depend on the number of $\mathrm{N}$ courses organized; $\mathrm{C}_{\text {promN }}=\mathrm{N} \times \mathrm{C}_{\text {prom; }}$

- e-learning support costs: $\mathrm{C}_{\mathrm{wbt}}$ - depend on the number of $\mathrm{N}$ courses organised; $\mathrm{C}_{\mathrm{wbtN}}=\mathrm{N} \times \mathrm{C}_{\mathrm{wbt}}$;

From these evaluations, it can be seen that:

- It is worthwhile organising more e-learning courses as the relative costs are much lower, and hardly any cost item in the new $\mathrm{N}$ course scenario is the same as $\mathrm{N}$ itself;

- Skills acquired on one course are easily recycled for other courses, notably for the e-tutor and ETM involved in the project;

- If a Faculty or University decides to adopt e-learning, it is recommended that groups with specific skills are organised to assist the teacher (ETM), administer the e-1 courses, manage student needs and assist the teaching staff with content management issues (communication, etc.).

\section{ROI including Start-up}

The classic formula of ROI shown in above can be used again with modifications regarding the values outlined over and using the cost values defined in the start-up phase, as shown in Equation 6:

$$
R O I=\frac{\text { Benefits }- \text { Costs }}{\text { Costs }} \times 100=\frac{B_{t o t}-C_{t o t S U}}{C_{t o t S U}} \times 100
$$

\section{ROI including start-up with an Open Source LMS}

It is evident, see Equation 7, that the start-up ROI will incur less costs when an Open Source platform is used as the Clms factor is eliminated, thus:

$$
R O I=\frac{\text { Benefits }- \text { Costs }}{\text { Costs }} \times 100=\frac{B_{t o t}-\left(C_{t o t S U}-C_{l m s}\right)}{\left(C_{t o t S U}-C_{l m s}\right)} \times 100
$$

\section{Determining the "e-IYI" Yield Index}

The final phase of the evaluation deals, as shown in equation 8, with the "e-lYI" Yield Index. Let us use the formula ROICL for the traditional F2F ROI and ROIe-1 for that determined in paragraph 10.4 or 10.7 depending on the LMS used.

We find, therefore:

$$
e-l Y I=\frac{R O I_{e-l}}{R O I_{C L}}
$$

As noted before, $e-l I R \phi 1$ defines a positive result in the methodology change toward elearning in the pilot course. The usefulness of this index is even greater when its effective value is considered (both in terms of cost and quality) in the use of an Open Source LMS which can significantly lower start-up costs without compromising the quality of the content, above all if the LMS used conforms to recognized standards such as SCORM (ADL SCORM http://www.adlnet.org). 


\section{Conclusions}

This study was made to better understand the chance of change in didactic methodologies for European universities, above all in south Italy universities, as well as the University of Bari. Once we understand completely how feasible this change is, we can try to suggest a good way to manage e-learning adopting some good instruments like "e-lYI".

The high costs for the production of the didactic materials to target "high quality e-learning" and the necessity to get an appropriate LMS to their implementation and diffusion, make proper the collaboration among different structures (universities and faculties). This collaboration foresees the compliance of the produced material to the international standards, such as SCORM, that assure the portability on the different operational environments.

The active role of the teams of administration and planning does not have to confine itself just to the project phase, but an evaluation during all the phases of the process is needed. In the planning phase and, subsequently, in service delivery phase, the operational management asks for a scrupulous check of goals needed.

The Yield Index "e-lYI" represents a valid tool of control and evaluation from the economic and qualitative point of view of the "e-learning project", because it is based on the study of the ROI, that is a factor for a long time used to these purposes but that does not succeed in being "absolutely" decisional for the "process transformation"; in fact ROI does not produce a quantitative comparison among the different methodologies (in our case F2F and e-learning) we can use to build a learning project. The Yield Index "e-lYI" has been studied for doing this quantitative comparison.

The purpose of environmental analysis/forecasting in academic planning is to provide college and University administrators information that can facilitate better decision-making, particularly in making decisions affecting the long-range future of their institutions. Given that we live in an age of "future shock," when changes in the educational environment occur with ever-increasing rapidity, educational leaders are faced with a future that most assuredly will be different from the present. This study has described a basic approach used to manage this uncertainty-identifying issues/concerns based upon experience and upon environmental scanning, producing alternative scenarios of plausible techniques that stimulate the development of viable and robust strategic options that can be incorporated in specific institutional plans.

\section{Acknowledgements}

This study was made as Master Thesis in "1st Master in Online Education and Training" at Bocconi University in Milan - Italy. The chairmen who helped the authors structuring and writing this paper were Prof. Jane Klobas (jane.klobas@uni-bocconi.it), and Prof. Stefano Renzi (stefano.renzi@uni-bocconi.it). The authors wish to thank them two for all the suggestions and for all the support given.

\section{References}

Allan, B. (2002). E-learning and teaching in library and information services. London: Facet.

Bracchi, G., Francalanci, C., \& Motta, G. (2003). Sistemi informativi e aziende in rete. McGrawHill.

Calvani, A., \& Rotta, M. (2000). Fare formazione in Internet. Erickson.

Clark, R. C., \& Mayer, R. E. (2003). E-learning and the science of instruction: Proven guidelines for consumers and designers of multimedia learning (1st ed.). San Francisco, CA: Jossey-Bass/Pfeiffer. 
Filetti, V., Marengo, A., Pioppi, A., Ropa, E., \& Uscidda, R. (2002). Il progetto corano. Bocconi University, Milan. from http://www.osel.it/marengo

Hall, B. \& LeCavalier, J. (2001). E-learning across the enterprise: The benchmarking study of best practices. Retrieved from http://www.brandonhall.com/public/publications/benchmarking/index.htm.

Henderson, A. J. (2003). The e-learning question and answer book: A survival guide for trainers and business managers. New York: American Management Association.

Holton, E., \& Baldwin, T. T. (2003). Improving learning transfer in organizations (1st ed.). San Francisco, CA: Jossey-Bass.

Horton, W. (2002). Designing Web Based Training. Wiley.

Jain, L. C., Howlett, R. J., Ichalkaranje, N. S., \& Tonfoni, G. (Eds.). (2002). Virtual environments for teaching \& learning. River Edge, N.J.: World Scientific.

Kossmann, D. (2004). Investing in learning: Consider value, not just ROI. Retrieved from http://www.clomedia.com/content/anmviewer.asp? $\mathrm{a}=464$.

Miller, C. \&Kulik, T. (2000). Knowledge management: Becoming an e-learning organization. New York: Conference Board.

Radiant Systems. (2002). Training: A critical success factor in implementing a technology solution. Retrieved from http://www.e-learningguru.com/wpapers/blended_radiant.pdf.

\section{Biographies}



Agostino Marengo, Faculty of Economics, University of Bari - Italy.

My research activity as Assistant Professor in Faculty of Economics at University of Bari, takes place primarily on didactic methodologies implemented by the use of ICT tools, particularly the development of e-learning web-based platforms that compete to introduce the technologies of distance learning in traditional institutional campus courses and activities.

As coordinator of OSEL (Open Source e-learning research project, http://www.osel.it), currently my research plan is to create a database of Open Source LCMSs in order to choose and compare them. The research group is actually involved in usability, accessibility and quality evaluation of LMS (Learning Management Systems) and CMS (Content Management Systems) with a special goal to evaluate Open Source e-learning platforms.



Vittorio Marengo, Faculty of Economics, University of Bari - Italy.

My research activity as Full Professor in University of Bari started with a research study on the analysis models of seismic waves data, in collaboration with Working Group Statistical Aspects of Seismicity inside European Seismological Commission (1972-1975).

Main research fields in my academic life are: Information Systems methodologies; optimization of models to transfer communication technologies; Database planning and design; Networking and Processing Systems; User-friendly tools for e-learning methodologies; Statistical methods for Data Mining.

Correspondence concerning this article should be addressed to Agostino Marengo, Faculty of Economics - University of Bari, Via C. Rosalba, 53, 70124 Bari (Italy). E-mail: amarengo@dss.uniba.it; Web page: http://www.osel.it/marengo 